\title{
Resistance and identity: homeless women's use of public spaces
}

\author{
Rionach Casey, Rosalind Goudie and Kesia Reeve* \\ Sheffield Hallam University
}

\begin{abstract}
This paper explores women's geographies of homelessness with a particular focus on homeless women's use of public spaces in England. It demonstrates that homeless women's spatial boundaries are not confined to the institutional spaces of homelessness, as much literature and research would suggest, but frequently extend into public spaces and buildings. The paper also argues that homeless women's use of public spaces can be conceptualised in terms of resistance: by occupying these spaces homeless women are challenging the rules governing public places which render them unwelcome there; and they are resisting a shift of identity arising from their homeless status.
\end{abstract}

Keywords: homelessness, gender, public space, identity, resistance.

\section{Introduction}

This paper focuses on women's geographies of homelessness through analysis of their use of non-homelessness public spaces and buildings. It foregrounds the 'presentation of self' (Goffman, 1959) which enables being in public space and the strategies used to negotiate the boundaries of the public realm. In doing so it attempts to capture a sense of personal agency and resistance (Parker and Fopp, 2004), suggesting that homeless women are not wholly constrained by structural and institutional barriers. As Foucault (1984) argues, there are no relations of power without the potential for resistance. A focus on the embodied human subject within the spaces of daily life, in other words on the mundane and everyday, provides a potential for exploring forms of resistance. It is important to note however, that the focus on agency does not imply the annulment of structural influences, or indeed the valorisation of homeless women's capacity to cope with their difficulties. Rather, it argues that given the highly constrained situations in which they find themselves, 
there is nonetheless a measure of resistance to spaces of exclusion that has yet to be articulated in the homelessness literature.

\section{Methodology and Sample}

The argument presented in this paper draws on research conducted in 2006 exploring women's experiences of homelessness. The study was commissioned by the homelessness charity Crisis in recognition that much homelessness research, while not explicitly gendered, tends to be dominated by the experiences and views of homeless men. Data collection focused initially on a questionnaire survey of 144 homeless women in 17 towns and cities in England. Respondents were living in a wide range of temporary accommodation situations including hostels, bed and breakfast hotels, refuges, squats and on the streets, and over 30 per cent were from minority ethnic groups. The majority (71 per cent) had been homeless for less than two years but a significant minority left their last settled home more than six years ago. The survey data were supplemented with in-depth interviews with 44 women homeless in Leeds, London, Sheffield and Norwich. Interviews took a biographical approach, exploring issues such as women's homelessness experiences, their daily lives and the relationship between their life histories and their homelessness. In-depth interview respondents ranged in age from 16 to 59, and 30 per cent were from minority ethnic groups.

Women become homeless from all and any settled housing situation, at all and any stage in their life course and so diversity in the situations and experiences of those interviewed was not surprising. Without wishing to deny such experiential diversity, a shared context of homelessness was apparent. For most of those interviewed, trajectories into and routes through homelessness were typically rooted in a context of personal difficulties, trauma, violence and marginalisation. Links between women's life experiences and subsequent homelessness were evident with the loss of a home clearly embedded in experiences of sexual abuse (in childhood and adulthood), neglect, abandonment and other family problems, experience of violence, and reproductive or maternal health issues. Drug and alcohol dependencies, mental ill health and coping difficulties frequently ensue and women's capacity to maintain a home or familial relationships is threatened. Once homeless, many women apparently struggle to negotiate access to adequate and appropriate service-led accommodation provision, with hidden homeless (i.e. non serviceled situations such as staying with friends, in squats and sleeping rough) extremely common amongst those interviewed.

This paper does not delve into the specifics of these situations and experiences or present detailed empirical evidence about the lives of the homeless women interviewed (full empirical findings can, however, be found in the report 'Homeless Women: still being failed yet striving to survive' which is available as a free download from Crisis.org.uk). Rather, it focuses very specifically on the role of public places in the lives of homeless women, and the strategies they employ to negotiate the (practical, emotional and ontological) impacts of homelessness.

\section{Homeless women and spaces of exclusion}

A review of relevant literatures suggests the exclusion of homeless women from public spaces. Homeless women are rarely, for example, acknowledged within the housing and 
homelessness literature as inhabiting public spaces and their geographies are typically portrayed as restricted to institutional homelessness spaces (such as night shelters, hostels and day centres) and, sometimes, to the streets. Thus Wardhaugh (1999) suggests that homeless women typically disappear in the shadows of institutional spaces of homelessness (p.203) while concluding that the streets are the 'quintessential male space' (Wardhaugh, 1999: 104). Indeed it has become an almost uncontested fact that "Women are much less likely than men to sleep on the streets, or in public places" (Smith, 2005). Women are portrayed as moving into the informal spaces of homelessness that punctuate the public spaces of the city only rarely or when under the protection of a man (Wardhaugh, 1999). In a similar vein, May et al. (2007), although presenting a more diverse view of homeless women's geographies also articulate a limited use of public space beyond the streets.

Other literatures conceptualise space in terms of legitimacy and exclusion - i.e. in terms of who is and who is not legitimately entitled to occupy different forms of spaces, or to whom particular spaces rightly 'belong'. Within this context much has been written about women's experiences of public space and gendered meanings of place. Contemporary research has theorised women's perceptions and use of public spaces as shaped primarily by gender constraints (Day, 2000). Women's 'distinctive relationship' with the home (i.e. private, domestic space), stemming from subjective aspects of individual (gendered) experience is also noted (Watson and Austerberry, 1986; Darke, 1991). Much of the theoretical focus of this literature is underpinned by the 'separation of spheres ideal', a Victorian concept which advocated the private domestic spaces for women and public spaces and activities for men. Literature which explores gendered meanings and perceptions of place, particularly that focused on 'the home' (whether as a site of power or oppression) tends to reinforce this association of women with family and home (the private realm) (see Mallett, 2004, for a useful discussion about home and gender). As Kemp, argues, “despite women's many....inroads into the public sphere...this gendered ideology continues to shape women's everyday lives, as well as social expectations about women's experiences and behaviour" (2001, p15). The difficulties this presents for women who are home-less is acknowledged by some homelessness scholars. In the context of exploring homeless women's perceptions, geographies and identities, Radley et al., for example, argue that it "remains transgressive for women to appear wherever they wish at whatever time” (2006, p456). Here, it is homeless women's gender which excludes them from rightfully consuming, or claiming public space.

On the other hand is the literature pointing to increased regulation of public space and the rules which govern and control these spaces - rules which typically disallow homeless peoples' presence. Here, it is not women's gender but their homelessness status which denies them use of public spaces. This point is made in various different ways by scholars of different disciplines and theoretical standpoints, but all suggest a form of legitimacy attached to public spaces which does not extend to homeless people and other marginalised groups. Some commentators argue that homeless people tend to be relegated to the marginal spaces of cities in terms of where they are tolerated or 'expected to be'. Inhabiting or moving through spatial domains associated with housed people is discordant with this urban order, contaminates public space, poses risks for the homeless person, and requires them to tactically find ways of 'being' in spaces from which they are excluded (Duncan, 1983; Snow and Mulcahy, 2001; Cloke et al., 2003). In the postmodern 'turn', cities are conceptualised as consumption spaces for the middle classes (Zukin, 1998), where environments are created to facilitate this consumption (Shields 
1989). Hence, homeless people - the ultimate 'flawed consumer' (Bauman, 2005), characterised as threatening by virtue of their difference (Sibley, 1995) - face rejection from these spaces.

How then, and in what ways, do homeless women, who are marginalised both by virtue of their gender and their homelessness status, use public space? Our research suggests that homeless women's geographies are certainly not limited to institutional spaces, and that their supposedly limited occupation of public space is not restricted to 'the streets' as much of the homelessness literature would imply. Far from remaining on the margins (Wardhaugh, 1999; May et al., 2007) many of the women participating in this study were frequent users of public spaces and were adept at being in, and using these spaces for their own needs. We also suggest that women's use of public spaces can be understood in terms of two key forms of resistance: challenging the rules of legitimacy regarding use of public space; and resisting homelessness identities.

\section{Homeless women in public spaces}

Public spaces, buildings and facilities featured heavily in the narratives of the women interviewed, and represented a key means through which they met their daily needs. Women occupied museums, galleries, parks, bookshops, libraries, public toilets (on-street and in buildings such as hospitals), public transport, car parks, art galleries, the streets, business and retail parks, airports, and the space surrounding public and private buildings (steps, grassed areas, bin bays, stairwells). They slept in these spaces, they ate, washed, rested, sheltered from harsh weather, laundered and changed their clothes, charged their mobile phones, and engaged in leisure activities (reading, listening to music). Far from existing 'in the shadows' or being restricted to the institutional spaces of homelessness these women were boldly, and often visibly, carrying out their daily functions (sleeping, washing, eating, relaxing) and meeting their needs out in public.

For many, these spaces and facilities represented an essential resource in the absence of (appropriate) service provision. Public places also, however, represented positive, viable, and preferable spaces of everyday life and survival: in some instances the public realm was perceived as safer than domestic spaces or institutional environments such as hostels or day centres, where it was not uncommon for homeless women to experience violence or feel threatened by the male dominated milieu of the homelessness service. Homelessness spaces can also represent a threat (or danger) to women's identity and perceptions of self - and issue we return to below.

\section{Homeless women's use of public spaces: forms of resistance}

We suggest that homeless women's use of public space can be conceptualised in terms of resistance. By occupying and utilising public spaces, homeless women are asserting their right to 'be' in these spaces and challenging the rules of legitimate occupancy which render them unwelcome there. Further, use of public spaces can be understood as an attempt by women to resist the absorption of homelessness into their identity and perceptions of self. 


\section{Challenging the rules of legitimacy regarding occupancy of public space}

Homeless people tend to be unwelcome in places such as libraries and galleries, parks and shopping centres, their presence a threat to the function of that space and the ('ordinary') people inhabiting it (Radley et al., 2007). Homeless people are out of place in this public realm, and homeless women even more so: a homeless woman carrying out daily activities (washing or sleeping, for example) in a non-domestic space is conceived as particularly disturbing and transgressive. Within this actual and theoretical context of exclusion women's use of public spaces can be understood as a form of resistance. They are not passively accepting the regulation of public space and the attached rules of usage, but resist their exclusion and the perceptions of gendered spatial belonging which deem them unwelcome, or out of place there. Homeless women find ways of asserting themselves and claiming a right to occupy space, challenging the geographical boundaries laid out for them and carving out a space in the public realm. Furthermore, they actively and strategically use these spaces to their own ends and for their own needs and purposes, extracting and deriving positive benefit from them.

To do so, however, requires a degree of ingenuity and resourcefulness. Being where one is not supposed to be, and doing what one is not supposed to do (body or clothes washing in public toilets, sleeping in libraries or on buses, for example) relies upon 'reading' the rules and devising strategies for circumventing them. It relies upon a (sometimes tacit) process of negotiation with the gatekeepers (security guards, wardens, attendants, shop staff) whose very function it is to uphold the rules governing use of the space which homeless women are attempting to subvert.

The women interviewed were adept at identifying these gatekeepers and behaving in ways which satisfied their informal rules to secure permission to use that space. Women recognised that their use of certain spaces would be tolerated at particular times of the day and always adhered to this (spoken or unspoken) arrangement. Thus one woman was 'allowed' to wash and brush her teeth in a public toilet every morning so long as she completed her ablutions before 7am. Remaining presentable and 'not looking homeless' was a typical condition of use and one woman described regularly watching security guards at an airport who had tolerated her presence for many months eject 'obviously' homeless people from the building. Sleeping upright and using a place only periodically were other strategies women employed to enable them access to and use of a wide range of public spaces, buildings and facilities.

Invisibility is central to many of these tactics and was a key requirement placed upon women by gatekeepers, whose primary concern was to protect legitimate service users from the homeless person's presence. Using public spaces at times of the day less popular with other service users, blending in by 'looking like everyone else', and disguising inappropriate activities (such as sleeping) can all be conceived as strategies of invisibility which allow both parties to hide the fact that a homeless woman is present in the space. Invisibility was also a key strategy employed by women to sleep rough, in this case as a safety strategy. In many instances this involved literal invisibility from public view with women choosing to sleep in types of spaces where they would not be seen such as enclosed public toilets, bin bays, and gated parks which are locked at night. But women also slept rough very visibly by rendering their homelessness status invisible. Thus the woman mentioned above who spent time in an airport slept many a night amongst hundreds of people, in full view of the general public and security staff, without any risk to her personal safety whatsoever. By remaining clean and presentable and carrying a small 
p. 95. Resistance and identity: homeless women's use of public spaces

bag which resembled holiday luggage she blended in perfectly and security staff were happy to turn a blind eye to her presence.

\section{Resisting homelessness identities}

Homeless women both adapt to, and resist a homelessness identity, and to being confined to the streets and to homelessness institutional spaces by engaging in identity work that enables them to be in highly visible public spaces and buildings through the presentation of self (looking clean and presentable), and being homeless within, rather than beyond the public gaze. In attempting to make sense of our findings Goffman's (1969) reading of identity seemed pertinent to conceptualising the strategies and processes by which these homeless women inhabit and move through public space. He asserts that most actors want to appear credible to others and want (or need) to make a good impression. Hence, the emphasis on tact, collusion, interactional damage limitation and repair. He asserts that identity is also marked by processes of claims and counter-claims, imposition and resistance. In particular he recognises 'spoiled identity' and the stigma that goes with it (1963).

The homeless women we interviewed were acutely aware of the stigma that was associated with being a woman without a home. Other people's reactions to them ranged from helpfulness to disdain and outright hostility, which impacted on how they saw themselves. However, they articulated a diversity of tactics and strategies in order to deal with being homeless and to get by from day-to-day, which suggests that there was some resistance to that 'spoiled' identity. These women managed the 'spoiled' identity associated with being homeless in ways that gave them a tenuous claim to be in public spaces that have heretofore been presumed out of bounds for marginalised inhabitants of urban spaces (Higate, 2000). They attempted to present themselves as legitimate users of public spaces in two ways: through the presentation of a 'respectable' self, which rendered their homelessness invisible and by dis-identifying with other more stigmatised homeless people. These women were alert to how stigmatised they were in the eyes of others and went to some lengths to avoid being easily identified as homeless. They also attempt to retain a sense of themselves, and their identities prior to becoming homeless, in a bid to 'salvage the self' (Snow and Anderson, 1993). This involved retaining the ability to care for themselves and their bodies and maintaining a measure of independence from institutional provision. They placed a lot of importance in personal hygiene and having clean clothes to wear in order that they could maintain some semblance of personal respect and also blend in with other customers and users of public buildings. Not wanting to be identified as being homeless also meant avoiding any outward 'signals' that would indicate such a status. Hence, not being seen carrying around sleeping bags or blankets assumed a critical importance in the day-to-day strategies of these women. They also spoke about hiding their personal effects and changes of clothes on their bodies in moving terms.

It was apparent that some homeless women were also trying to distance themselves from other homeless people to whom an even greater stigma was attached, for example, those who were drug users, 'smack-heads' and prostitutes, by presenting a 'respectable' appearance. These homeless women were concerned that they would not all be seen in the same light by virtue of their homelessness, and had a clear idea of what they would or would not do in order to get by. Part of the strategy that was needed to maintain a valorised sense of self while being homeless was the avoidance of behaviour that for them 
p. 96. Resistance and identity: homeless women's use of public spaces

was identified with archetypal male homelessness, such as picking cigarette butts off the ground and rooting around in rubbish bins. They also distanced themselves from prostitutes, both for their own personal safety and in order to challenge the assumption that all homeless women were engaged in sex work. They avoided using facilities such as phone boxes at certain times, and stayed away from areas if there was any possibility they would be mistaken for prostitutes. Nonetheless, they still had to confront this particular myth on a regular basis, which had a significant impact on their use of public space, particularly at night.

\section{Conclusions}

Our findings suggest that strategies of resistance and identity are being played out beyond the streets (as in Wardhaugh 1999, and May et al. 2007), thereby expanding homeless women's spatial boundaries into semi-private and highly visible public spaces (which heretofore were presumed to be closed to them). Their resistance is inextricably bound up with where they can 'be' and 'do' homelessness, and the legitimacy of their claims to being in public spaces and buildings. Homeless women not only occupy public spaces for their own ends and purposes, but are adept at negotiating access with gatekeepers, and moving between visibility and invisibility in order to do so. These women's strategies to secure some measure of autonomy are mediated by their own construction of what it means to be homeless and female, which is not fixed in time and space, and which is shaped by 'significant others'.

\section{Acknowledgements}

We gratefully acknowledge Crisis for funding the research on which this paper is based, and to colleagues Paul Hickman and Peter Wells for their helpful comments on the first draft. We would also like to thank all the homeless women who participated in the study.

* Correspondence Address: Rionach Casey, Rosalind Goudie and Kesia Reeve, Centre for Regional Economic and Social Research, Sheffield Hallam University, Unit 10, Science Park, Howard Street, S1 1WB, UK. Email: r.casey@shu.ac.uk / r.goudie@shu.ac.uk / k.reeve@shu.ac.uk. 
p. 97. Resistance and identity: homeless women's use of public spaces

\section{References}

Bauman, Z. (2005) Work, Consumerism and the New Poor. London: OUP

Cloke, P., Johnsen, S. and May, J. (2003) Journeys and Pauses: Tactical and Performative Spaces in the Homeless City.

Darke, J. (1991) Women and the Meaning of Home in: Gilroy, R. and Woods, R. (eds) Housing Women. London: Routledge.

Day, K. (2000) The Ethic of Care and Women's Experiences of Public Space. Journal of Environmental Psychology, 20, 103-124.

Duncan, J. S. (1983) Men without Property: The Tramp's Classification and use of Urban Space, in: Lake, R. W. (ed.) Readings in Urban Analysis. New Brunswick: Rutgers University Press.

Foucault, M. (Rabinow, P, Ed) (1984) The Foucault Reader. London: Penguin Books.

Goffman, E. (1959) The Presentation of Self in Everyday Life. Harmondsworth: Penguin Books.

Goffman, E. (1963) Stigma: Notes on the Management of Spoiled Identity. Harmondworth: Pelican Books.

Jenkins, R. (1996) Social Identity. London and New York: Routledge.

Kemp, S. P. (2001) Environment through a Gendered Lens: From Person-in Environment to Woman-in Environment. Affilia, Journal of Women in Social Work, 16, 1, 7 - 30.

Mallett, S. (2004) Understanding Home: A Critical Review of the Literature. Sociological Review, 52, 1, 62-89.

May, J., Cloke, P. and Johnsen, S. (2007) Alternative Cartographies of Homelessness: rendering visible British women's experiences of 'visible' homelessness. Gender, Place and Culture, 14, 2, 121-140.

Parker, S. and Fopp, R. (2004) I'm the Slice of the Pie that's Ostracised....' Foucault's Technologies and Personal Agency, in: the Voice of Women who are Homeless, Adelhaide, South Australia'. Housing, Theory and Society, 21, 4, 145-154.

Radley, A., Hodgetts, D. and Cullen, A. (2007) Fear, Romance and Transience in the Lives of Homeless Women. Social and Cultural Geography, 7, 3, 437-461.

Shields, R. (1989) Social Spacialisation and the Built Environment: the West Edmonton Mall. Environment and Planning: D: Society and Space, 7, 2, 147-164.

Sibley (1995) Geographies of Exclusion. London: Routledge.

Smith, J. (2005) Housing, Gender and Social Policy, in: Somerville P. and Sprigings, N. (eds) Housing and Social Policy: Contemporary Themes and Critical Perspectives. Oxon: Routledge.

Snow, D. A. and Anderson, L. (1993) Down on Their Luck: A Study of Homeless Street People. Berkley: University of California Press.

Snow, D. A. and Mulchahy, M. (2001) Space Politics and the Survival Strategies of the Homeless. American Behavioural Scientist, 45, 149 -168.

Wardhaugh, J. (1999) The Unaccommodated Woman: Home, Homelessness and Identity. The Sociological Review, 47, 1, 91-109.

Watson, S. and Austerberry, H. (1986) Housing and Homelessness: A Feminist Perspective. London: Routledge \& Kegan Paul.

Zuchin, S. (1998) Urban Lifestyles: Diversity and Standardisation in Spaces of Consumption. Urban Studies, 35, 5-6, 825-839. 